NIST Special Publication 1200-19

\title{
GC-MS/MS Measurement of Nanomaterial- Induced DNA Modifications in Isolated DNA
}

Version 1.0

Bryant C. Nelson

Elijah J. Petersen

Pawel Jaruga

Miral Dizdaroglu

This publication is available free of charge from:

http://dx.doi.org/10.6028/NIST.SP.1200-18 
NIST Special Publication 1200-19

\title{
GC-MS/MS Measurement of Nanomaterial- Induced DNA Modifications in Isolated DNA
}

Version 1.0

\author{
Bryant C. Nelson \\ Elijah J. Petersen \\ Material Measurement Laboratory \\ Biosystems and Biomaterials Division \\ Pawel Jaruga \\ Miral Dizdaroglu \\ Material Measurement Laboratory \\ Biomolecular Measurement Division
}

This publication is available free of charge from:

http://dx.doi.org/10.6028/NIST.SP.1200-19

November 2015

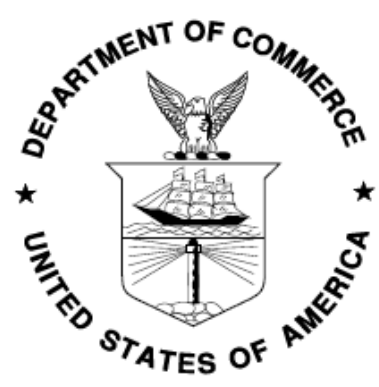

U.S. Department of Commerce

Penny Pritzker, Secretary

National Institute of Standards and Technology

Willie May, Under Secretary of Commerce for Standards and Technology and Director 
Certain commercial entities, equipment or materials may be identified in this document in order to describe an experimental procedure or concept adequately. Such identification is not intended to imply recommendation or endorsement by the National Institute of Standards and Technology, nor is it intended to imply that the entities, materials or equipment are necessarily the best available for the purpose.

National Institute of Standards and Technology Special Publication 1200-19 Natl. Inst. Stand. Technol. Spec. Publ. 1200-19, 17 pages (November 2015) CODEN: NSPUE2

This publication is available free of charge from: http://dx.doi.org/10.6028/NIST.SP.1200-19 


\section{FOREWORD}

This special publication is one in a series stemming from the National Nanotechnology Initiative (NNI) Nano-EHS Research Strategy which identified Nanomaterial Measurement Infrastructure as one of the essential areas of research needed in order to develop an effective risk assessment and management plan regarding various aspects of nanotechnology in consumer products as it pertains to human health, exposure and the environment. The National Institute of Standards and Technology (NIST) was identified as a lead agency in the development of measurement strategies for the robust development to assess the potential effects of engineered nanomaterials and their fate in the environment. One important endpoint for measuring the potential human health and ecological effects of nanomaterials is the extent of modification that may occur on DNA bases, nucleosides or nucleotides. These modifications are considered to be DNA damage and may be relevant for the risk assessment of nanomaterials in biological systems.

The current protocol presents a method to measure nanomaterial induced DNA damage levels using gas chromatography/tandem mass spectrometry with isotope-dilution. Updates to this protocol may be released in the future. Visit http://nist.gov/mml/np-measurement-protocols.cfm to check for revisions of this protocol, or new protocols in the series. We also encourage users to report citations to published work in which this protocol has been applied. 


\section{Introduction}

Making accurate measurements of the environmental fate and environmental and biological effects of engineered nanomaterials (ENMs) is critical for reliable risk assessment of these materials. It has been shown that ENMs can induce DNA damage through oxidative stress in living systems and/or through direct binding of ENMs to DNA. However, the unique behaviors of ENMs may cause measurement artifacts during the determination of their DNA damaging potential [1]. For example, results from several DNA damage studies using the traditional Comet assay have reported artifacts from the presence of ENMs [2-6]. Potential explanations for this phenomenon are that ENMs may induce DNA damage during processing after the exposure period has concluded or that the ENMs may be in the Comet tail and mistaken for DNA. These types of measurement artifacts preclude the accurate measurement of DNA damage and prevents researchers from clarifying the fundamental mechanisms of ENM induced DNA modifications [2].

In this document, we describe a protocol to quantitatively measure a range of DNA lesions using isotope-dilution gas chromatography/tandem mass spectrometry (GC-MS/MS) and NIST standard reference material (SRM) 2396 (Oxidative DNA Damage Mass Spectrometry Standards). This method circumvents many of the artifacts observed in the Comet DNA strand break assay by directly quantifying molecular level DNA damage (i.e., DNA lesion) for a range of oxidatively induced damage products. Isotope-dilution mass spectrometry methods have been recently utilized by our laboratory to successfully measure DNA damage both in vitro and in vivo caused by gold nanoparticles [7], copper oxide nanoparticles [8], single-wall carbon nanotubes [9], iron oxide nanoparticles [10], titanium dioxide nanoparticles [11] and silver nanoparticles [12].

\section{Principles and Scope}

This protocol is proposed for the measurement of DNA lesion levels using GC-MS/MS with isotope-dilution [13] after exposure of isolated DNA to ENMs. Methods for determination of DNA lesion levels after cellular or whole organism exposure to ENMs are similar but are not described in the present protocol. Not all possible forms of DNA damage can be measured by this approach. This protocol focuses specifically on oxidatively-induced damage to DNA bases. The methodology, and specifically the instrumentation described in the present protocol, is based on the accurate measurement of DNA base lesions using a triple quadrupole mass analyzer in multiple reaction monitoring (MRM) mode (see Table A). The MRM transitions for each base lesion are specifically given in section 6.2 below. A similar protocol for the quantification of DNA base lesions that describes the use of a single quadrupole mass analyzer and selected ion monitoring for the measurement of ENM induced DNA damage also exists, but this protocol exists as a separate document. Usage of stable isotope-labeled internal standards (ISTDs) from SRM 2396 enables absolute identification and quantification of the following DNA lesions: 4,6diamino-5-formamidopyrimidine (FapyAde), 2,6-diamino-4-hydroxy-5-formamidopyrimidine (FapyGua), 8-hydroxyadenine (8-OH-Ade), 5-hydroxycytosine (5-OH-Cyt), 5-hydroxyuracil (5OH-Ura), 5-(hydroxymethyl)uracil (5-(OHMe)Ura), thymine glycol (ThyGly) and 5-hydroxy-5methylhydantoin (5-OH-5-MeHyd). Other important DNA lesions such as 8-hydroxyguanine (8$\mathrm{OH}-\mathrm{Gua}$ ) can also be measured with this approach by hydrolyzing 8-hydroxy-2-deoxyguanosine-

${ }^{15} \mathrm{~N}_{5}$ ISTD in SRM 2396 to 8-hydroxyguanine- ${ }^{15} \mathrm{~N}_{5}\left(8-\mathrm{OH}\right.$-guanine- $\left.{ }^{15} \mathrm{~N}_{5}\right)$ or stable isotope- 
labeled versions of 8-OH-Gua may be synthesized directly [14]. In this procedure, 8-OHguanine- ${ }^{15} \mathrm{~N}_{5}$ is obtained by hydrolysis of 8-hydroxy-2-deoxyguanosine- ${ }^{15} \mathrm{~N}_{5}$ with $60 \%$ formic acid at $140{ }^{\circ} \mathrm{C}$ for $30 \mathrm{~min}$ followed by lyophilization. Subsequently, 8 -OH-guanine- ${ }^{15} \mathrm{~N}_{5}$ is dissolved in $10 \mathrm{mM} \mathrm{NaOH}$ and its concentration in solution is determined using $\mathrm{UV}$ spectrophotometry prior to use.

Table A DNA lesions detected and quantified by different MS procedures.

\begin{tabular}{|c|c|c|c|}
\hline Lesion \# & $\begin{array}{c}\text { GC/MS } \\
\text { (bases by SIM) }\end{array}$ & $\begin{array}{c}\text { GC-MS/MS } \\
\text { (bases by MRM) }\end{array}$ & $\begin{array}{c}\text { LC-MS/MS } \\
\text { (nucleosides by MRM) }\end{array}$ \\
\hline 1 & FapyAde & FapyAde & 8-OH-dGuo \\
\hline 2 & FapyGua & FapyGua & $R$-cdAdo \\
\hline 3 & 8-OH-Ade & 8-OH-Ade & $R$-cdAdo \\
\hline 4 & 5-OH-Cyt & 5-OH-Cyt & $S$-cdGuo \\
\hline 5 & 5-OH-Ura & 5-OH-Ura & \\
\hline 6 & 5-(OHMe)Ura & 5-(OHMe)Ura & \\
\hline 7 & ThyGly & ThyGly & \\
\hline 8 & 5-OH-5MeHyd & 5-OH-5MeHyd & \\
\hline 9 & 8-OH-Gua & 8-OH-Gua & \\
\hline
\end{tabular}

1. Base lesions detected and quantified in the present protocol.

\section{Terminology}

This protocol complies with definitions relevant to nanotechnology as set forth in the ASTM International E2456 [15] and is consistent with the draft standard ISO TS 80004-1:2010 [16]. nanoparticle - sub-classification of ultrafine particle that is characterized by dimensions in the nanoscale (i.e., between approximately $1 \mathrm{~nm}$ and $100 \mathrm{~nm}$ ) in at least two dimensions; also referred to as "nano-object" in ISO TS 80004-1:2010 [16].

primary particle - the smallest discrete identifiable entity associated with a particle system; in this context, larger particle structures (e.g., aggregates and agglomerates) may be composed of primary particles.

aggregate - a discrete assemblage of primary particles strongly bonded together (i.e., fused, sintered, or metallically bonded).

Note-The adjective "primary", when used in conjunction with the term aggregate, is employed in the present context to indicate the smallest achievable dispersed particle entity.

agglomerate - assemblage of particles (including primary particles and/or smaller aggregates) held together by relatively weak forces (e.g., van der Waals, capillary, or electrostatic), that may break apart into smaller particles upon further processing.

Note-Although we define them as distinct entities, the terms aggregate and agglomerate have often been used interchangeably to denote particle assemblies.

dispersion - used in the present context to denote a liquid (aqueous) in which particles are homogeneously suspended, or the process of creating a suspension in which discrete particles are homogeneously distributed throughout a continuous fluid phase; implies the intention to break down agglomerates into their principal components (i.e., primary particles and/or aggregates). 


\section{Materials and equipment}

\subsection{Reagents}

\subsubsection{NIST SRM 2396}

4.1.2 Distilled and deionized $\cong 18 \mathrm{M} \Omega$ water $\left(\mathrm{ddH}_{2} \mathrm{O}\right)$, e.g., Millipore Milli-Q; sterile DNase/RNase-free water is recommended (e.g., Ambion, non-DEPC treated)

4.1.3 Dried genomic DNA (e.g., calf thymus DNA, Sigma-Aldrich) or oligomeric DNA (e.g., Integrated DNA Technologies)

4.1.4 Absolute anhydrous ethanol, (e.g., Sigma-Aldrich, $<0.005 \%$ water)

4.1.5 $\mathrm{Fpg} / \mathrm{Nth}$ buffer $(50 \mathrm{mmol} / \mathrm{L}$ sodium phosphate, $100 \mathrm{mmol} / \mathrm{L}$ potassium chloride, 1 $\mathrm{mmol} / \mathrm{L}$ ethylenediaminetetraacetic acid (EDTA), $0.1 \mathrm{mmol} / \mathrm{L}$ dithiothreitol (DTT), and adjusted to $\mathrm{pH} 7.4$ using $\mathrm{ddH}_{2} \mathrm{O}$ )

4.1.6 DNA repair enzymes (e.g., Fpg or Nth, Trevigen)

4.1.7 Liquid nitrogen

4.1.8 Pyridine (e.g., Sigma-Aldrich with a minimum purity of $99 \%$, stored in a amber glass vial with a few pellets of $\mathrm{KOH}$ to help remove water)

4.1.9 Bis(trimethylsilyl)trifluoroacetamide + $1 \%$ trimethylchlorosilane (BSTFA + TMCS, e.g., ThermoScientific Corp with a minimum purity of $99 \%$ )

4.1.10 Acetonitrile (e.g., Sigma-Aldrich with a minimum purity of $99.9 \%$, anhydrous)

4.1.11 High purity (99.999 \%) nitrogen gas (e.g., Airgas Inc.)

4.1.12 ENMs (e.g., NIST SRM 8011, 8012, 8013, etc.)

\subsection{Materials}

4.2.1 $15 \mathrm{~mL}$ centrifuge tubes

4.2.2 Glassware for making ICP-MS measurements

4.2.3 Calibrated pipettes and disposable tips

4.2.4 Quartz cuvettes for UV/Vis measurements

4.2.5 Drierite desiccant

4.2.6 $2 \mathrm{~mL}$ glass autosampler vials with caps and low volume $(300 \mu \mathrm{L})$ inserts

4.2.7 Chelex 100 resin (e.g., Sigma-Aldrich)

\subsection{Equipment}

4.3.1 Fixed angle refrigerated centrifuge that is capable of spinning up to $20000 \mathrm{xg}$ and which is suitable for $2 \mathrm{~mL}$ Eppendorf sample tubes

4.3.2 Vortex mixer

4.3.3 Double beam UV/Vis absorbance spectrophotometer or another instrument capable of quantifying DNA concentrations

4.3.4 Speed Vac system capable of holding $2 \mathrm{~mL}$ Eppendorf sample tubes or $2 \mathrm{~mL}$ glass autosampler vials or a vacuum desiccator

4.3.5 Horizontal shaker with speed control

4.3.6 Orbital rotator with speed control

4.3.7 $3500 \mathrm{MWCO}$ dialysis membrane

4.3.8 $2 \mathrm{~mL}$ Eppendorf sample tubes 
4.3.9 Lyophilizer

4.3.10 $4{ }^{\circ} \mathrm{C}$ refrigerator

4.3.11 $-20^{\circ} \mathrm{C}$ freezer

4.3.12 $-80^{\circ} \mathrm{C}$ freezer

4.3.13 Oven that can reach $120^{\circ} \mathrm{C}$

4.3.14 Triple quadrupole gas chromatography/mass spectrometry (GC/MS/MS) system with an electron ionization source. The system should have a mass range of $10 \mathrm{Da}$ to $1050 \mathrm{Da}$, a scan speed of $6250 \mathrm{Da} / \mathrm{s}$ and a transition speed of $500 \mathrm{MRMs} / \mathrm{s}$

4.3.15 Single quadrupole inductively coupled plasma/mass spectrometry (ICP/MS) system with nickel cones and a Conikal nebulizer or a suitable single quadrupole inductively coupled plasma/optical emission spectrometry (ICP/OES) system

\section{Treatment of and removal of ENMs from laboratory prepared DNA stock solutions.}

\subsection{Preparation of DNA stock solutions}

5.1.1 To a known mass of dried DNA in a $15 \mathrm{~mL}$ plastic centrifuge tube, add a known volume fraction of $\mathrm{ddH}_{2} \mathrm{O}$ so that the final concentration of DNA in the tube is $\leq 500 \mu \mathrm{g} / \mathrm{mL}$.

5.1.2 Place the tube on an orbital rotator in a $4{ }^{\circ} \mathrm{C}$ refrigerator and gently mix the DNA solution for $72 \mathrm{~h}$ to ensure complete solubilization.

5.1.3 Treat the solubilized DNA with Chelex 100 resin to remove heavy metals and divalent transition metals.

5.1.4 Dialyze (3500 MWCO membrane, $25 \mathrm{~mm}$ to $30 \mathrm{~mm}$ diameter) the DNA against $\mathrm{ddH}_{2} \mathrm{O}$ at $4{ }^{\circ} \mathrm{C}$ for $24 \mathrm{~h}$ and change the water at least twice during this time period.

5.1.5 Determine the concentration of the solubilized DNA using UV/Vis spectrophotometry (1 absorbance unit equals $50 \mu \mathrm{g} / \mathrm{mL}$ double-stranded DNA at $260 \mathrm{~nm}$ ). For the stock DNA solution, it is recommended that the user also check the purity of the DNA solution by quantitatively evaluating the total RNA and protein levels in the sample. An estimate of RNA contamination can be quickly obtained by evaluating the $260 \mathrm{~nm} / 280 \mathrm{~nm}$ ratio for the sample. A ratio of 1.8 to 2.0 indicates pure DNA while values higher than 2.0 suggests RNA contamination. Total RNA contamination can be quantitatively evaluated using the Qubit fluorescence assay [17]. Proteins absorb at $280 \mathrm{~nm}$ but the absorbance at $280 \mathrm{~nm}$ has a minimal effect on the $260 \mathrm{~nm} / 280 \mathrm{~nm}$ ratio due to the much higher extinction coefficient of nucleic acids at both $260 \mathrm{~nm}$ and $280 \mathrm{~nm}$. However, protein levels in the DNA solution can be quantitatively assessed using either the Lowry [18] or Bradford [19] protein assays.

5.1.6 Store the DNA stock solution at $4{ }^{\circ} \mathrm{C}$ until needed or proceed directly to treating the DNA with ENMs based on the experimental design.

\subsection{Treatment of DNA solutions with ENMs}

5.2.1 To $2 \mathrm{~mL}$ Eppendorf sample tubes, add an appropriate volume of DNA stock solution so that the total mass of DNA in each tube is $100 \mu \mathrm{g}$.

5.2.2 Add a specified volume of dispersed ENM and additional dispersant into each sample tube so that an appropriate range of ENM sample concentrations are obtained. 
5.2.3 Prepare both positive and negative control samples using an identical procedure, as well as a dispersant-only control sample. All test and control samples should be prepared in triplicate. Prepare extra sets of triplicate control samples that are both unspiked and spiked $(50 \mathrm{mg} / \mathrm{L})$ with the highest ENM concentration under investigation. These samples will be used for verification/quantification of ENM removal via ICP-MS or ICPOES (see below).

5.2.4 Treat all of the samples as necessary (i.e., expose to light/dark, heat/cold, adjust $\mathrm{pH}$, sonicate, etc.,) for the specified period of time based on the experimental design.

\subsection{Removal of ENMs from DNA solutions}

5.3.1 Removal of the ENMs from the DNA samples is performed based upon centrifugation followed by ICP-MS quantitative verification of ENM removal. In some instances, it may be appropriate to utilize ICP-OES analyses if elemental detection sensitivity is not a limiting factor.

5.3.2 Centrifuge the samples at $16000 \mathrm{~g}(14000 \mathrm{rpm})$ for $1 \mathrm{~h} @ 4{ }^{\circ} \mathrm{C}$ to pellet the ENMs. This procedure has been shown to be suitable for metal (i.e., AuNPs [7]) and metal-oxide (i.e., $\mathrm{TiO}_{2} \mathrm{NPs}$ [11]) ENMs with a minimum diameter of $10 \mathrm{~nm}$. Using this centrifugation procedure, $\cong 98 \%$ of the ENMs can be removed from solubilized DNA samples. If less than $98 \%$ of the ENMs are removed from the DNA, then one simply increase the centrifugation time. (Appendix shows validation data for removal of AuNPs (Figure 1) and removal of $\mathrm{TiO}_{2} \mathrm{NPs}$ (Table 1). Please see references above for additional details.

5.3.3 Transfer the DNA supernatants into $30 \mathrm{kDa}$ molecular-weight-cutoff (MWCO) centrifugal filter units and centrifuge the samples at $7000 \mathrm{~g}$ for $15 \mathrm{~min} @ 4{ }^{\circ} \mathrm{C}$.

5.3.4 Wash the filter membrane with $\mathrm{ddH}_{2} \mathrm{O}$ then reverse-elute the DNA into a clean $1.5 \mathrm{~mL}$ Eppendorf tube.

5.3.5 Determine the concentration of the eluted DNA solution using UV spectrophotometry (1 absorbance unit $=50 \mu \mathrm{g}$ DNA $/ \mathrm{mL}$ at $260 \mathrm{~nm}$ ) and store the collected samples at $4{ }^{\circ} \mathrm{C}$ or proceed directly to the addition of the isotopically labeled internal standards to each of the samples (see below). The accuracy of the DNA quantification method can be tested using NIST SRM 2372 (DNA Quantitation Standard).

5.3.6 Verify the level of ENM removal using only the spiked control and unspiked control samples via ICP-MS analysis as follows: add a suitable internal standard to each sample and digest each sample using for example: a 3:1 volume fraction mixture of concentrated $\mathrm{HCl} / \mathrm{HNO}_{3}\left(30 \mathrm{~min} @ 75^{\circ} \mathrm{C}\right.$ with orbital shaking at $\left.1 \mathrm{~s}^{-1}(60 \mathrm{rpm})\right)$. This digestion solution will work for AuNPs, but the analyst may need to modify this solution for other metal or metal-oxide-based ENMs.

5.3.7 Cool the control samples down to room temperature and dilute them with $3 \% \mathrm{HCl}+1 \%$ $\mathrm{HNO}_{3}$ as required for analysis. Note: the sample digestion and dilution solutions will change depending on the element of interest.

5.3.8 Perform elemental analysis on the digested control samples using ICP-MS. Based on the elemental calibration response factor, determine the elemental response in the spiked and unspiked control samples. Determine the mean level of ENM removal from the DNA solutions. 


\section{DNA lesion measurements using GC/MS/MS}

\subsection{DNA lesion quantification procedure}

6.1.1 Transfer the required volume of eluted DNA from the centrifugal filter unit (see above) into a $1.5 \mathrm{~mL}$ Eppendorf tube so that the tube contains at least $50 \mu \mathrm{g}$ of DNA. If there is not enough DNA sample volume to add $50 \mu \mathrm{g}$ to each sample, add at least $30 \mu \mathrm{g}$. It is important to use the same DNA mass for all samples in a sample set.

6.1.2 Add the relevant isotopically labeled internal standards to each vial. We recommend also testing a reference DNA such as calf thymus DNA and an internal standard mixture sample during each sample set analysis to test assay performance. These control samples are used to confirm the retention time and analyte peak stability of the GC column and to help assess the performance of the mass analyzer. The concentration of internal standard to add for each of the lesions depends on the type of DNA (i.e., isolated DNA, cellular DNA, etc.) and on the dynamic range of the GC/MS/MS instrument. This needs to be tested during preliminary experiments with reference DNA. If too low or too high of an internal standard concentration is used, it may be challenging to integrate the peaks for the internal standard or the calibrated measurement range of the instrument may be exceeded.

6.1.3 Dry the samples using either a Speed Vac or vacuum desiccator. After the samples are dry, either begin the next step or store the samples at $4^{\circ} \mathrm{C}$ in a jar with desiccant.

6.1.4 Add $50 \mu \mathrm{L}$ of Fpg/Nth buffer to each sample and incubate all samples at room temperature with gentle rocking for $\geq 4 \mathrm{~h}$ (do not vortex mix samples). The Fpg/Nth buffer is prepared by adding the following ingredients to $\mathrm{ddH}_{2} \mathrm{O}(50 \mathrm{mmol} / \mathrm{L}$ sodium phosphate, $100 \mathrm{mmol} / \mathrm{L}$ potassium chloride, $1 \mathrm{mmol} / \mathrm{L}$ EDTA, and $0.1 \mathrm{mmol} / \mathrm{L}$ DTT) and adjusting the $\mathrm{pH}$ to 7.4 .

6.1.5 If the lesion levels for 8-OH-Gua are going to be tested, add the internal standard for this lesion at this point. 8-Hydroxyguanine is more readily oxidized than the other internal standards and is thus added at this step instead of in step 6.1.2. The concentration of the 8-OH-Gua internal standard to be added should be determined by UV spectrophotometry before use due to its limited stability.

6.1.6 Add Nth and/or Fpg to the samples. These enzymes are commercially available and can also be prepared using recombinant methodology [20]. The concentration of enzyme(s) to be added should be determined during preliminary experiments by adding a range of concentrations and assessing the optimal concentration for maximum excision of oxidized lesions.

6.1.7 Briefly centrifuge the samples at $1000 \mathrm{~g}$ for $30 \mathrm{~s}$ at room temperature to ensure that all of the solution is at the bottom of the container.

6.1.8 Incubate the samples at $37^{\circ} \mathrm{C}$ for $1 \mathrm{~h}$ (water bath).

6.1.9 Stop the reaction by adding $150 \mu \mathrm{L}$ of absolute cold ethanol and briefly vortex mix each sample. This step will precipitate the unreacted DNA glycosylases and the undigested DNA (DNA containing non-modified bases).

6.1.10 Incubate all samples at $-20{ }^{\circ} \mathrm{C}$ for $1 \mathrm{~h}$ or overnight.

6.1.11 Centrifuge all samples at $15800 \mathrm{~g}$ for $30 \mathrm{~min}$ at $4^{\circ} \mathrm{C}$.

6.1.12 Transfer supernatant $(185 \mu \mathrm{L})$ into clear crimp-top glass autosampler vials. Leave the undigested DNA at the bottom of the Eppendorf tube. 
6.1.13 Remove the ethanol from the autosampler vials by placing the vials in the Speed Vac or in a vacuum desiccator. Preliminary experiments can be conducted to find the time needed to fully remove the ethanol.

6.1.14 Add $200 \mu \mathrm{L}$ of $\mathrm{ddH}_{2} \mathrm{O}$ to each sample and cover the glass vials using tissue and rubber bands. The tissue prevents the ice from flying out of the vials. Insert the samples into a round glass sample holder and freeze all samples using liquid nitrogen. Pour off the excess liquid nitrogen from the round glass vial holder. Alternatively, the samples can be frozen in a freezer at $-80^{\circ} \mathrm{C}$ for at least half an hour. Dry all samples overnight (minimum of $16 \mathrm{~h}$ ) using a freeze dryer. Freeze drying does not form precipitates, instead a film of DNA should cover the bottom quarter of the vial at the end of the drying step.

6.1.15 Store the samples at room temperature in a glass jar containing fresh desiccant or proceed directly to derivatization which starts in the next step.

6.1.16 Turn on an oven and let it warm up to $120{ }^{\circ} \mathrm{C}$. Remove BSTFA from the refrigerator at 4 ${ }^{\circ} \mathrm{C}$ and let it warm up for $10 \mathrm{~min}$ at room temperature.

6.1.17 Derivatize analytes to trimethylsilyl esters by adding $30 \mu \mathrm{L}$ of BSTFA and $30 \mu \mathrm{L}$ of pyridine to each sample vial.

6.1.18 Cover each sample with a light stream of high purity nitrogen $(99.999 \%)$ for $\cong 10 \mathrm{~s}$, close sample vials and vortex for $\cong 5 \mathrm{~s}$. Make sure that the vial caps are on tightly to prevent oxygen from getting into the sample vials. Try to twist the caps to make sure they are secure. Note: connect an oxygen and moisture removal cartridge to the outlet of the high purity nitrogen supply to ensure the purity of the nitrogen entering the samples.

6.1.19 Incubate samples at $120^{\circ} \mathrm{C}$ for $30 \mathrm{~min}$.

6.1.20 Allow samples to cool for approx. $15 \mathrm{~min}$ (leave them on a lab bench).

6.1.21 Transfer samples into GC/MS autosampler vials (containing low-volume inserts) with syringe (wash syringe with acetonitrile solution after each sample transfer).

6.1.22 Cover samples with a light stream of nitrogen for $\cong 10 \mathrm{~s}$ and crimp-cap.

6.1.23 Analyze the samples using GC/MS/MS methodology [21-23].

\subsection{GC/MS/MS sample analyses}

6.2.1 The GC/MS/MS sample analyses are performed on a high resolution triple quadrupole GC/MS/MS system operated in positive ion mode with an electron ionization source.

6.2.2 The GC column is an HP-Ultra 2 high-resolution fused silica capillary column (12.5 m, $0.2 \mathrm{~mm}$ i.d.) coated with cross-linked $5 \%$ phenylmethylsilicone gum phase (film thickness, $0.33 \mu \mathrm{m})$ (Agilent Technologies).

6.2.3 Gas chromatography separation of the derivatized lesions is performed with a temperature programmed ramp from $130{ }^{\circ} \mathrm{C}$ to $300^{\circ} \mathrm{C}\left(130{ }^{\circ} \mathrm{C}, 2\right.$ min hold, $8{ }^{\circ} \mathrm{C}$ per min to $207{ }^{\circ} \mathrm{C}, 0 \mathrm{~min}$ hold; $10{ }^{\circ} \mathrm{C}$ per min to $300{ }^{\circ} \mathrm{C}, 4 \mathrm{~min}$ hold). The total run time is 24.75 min. The sample injection amount is $5 \mu \mathrm{L}$.

6.2.4 Trimethylsilyl derivatives of each DNA lesion and their stable isotope-labeled analogue are detected in MRM mode after appropriately tuning and optimizing the MS/MS instrument and analyte detection parameters. Each manufacturer's instrument will have a different detection sensitivity for the analytes and thus the analytes will have to be tuned independently. Typical instrument parameters that need to be tuned and optimized for the derivatized analytes are the following: analyte dwell time, collision gas flow rate, 
collision cell RF voltage, collision cell hexapole voltage, collision cell entrance voltage, collision cell exit voltage, injection mode, split ratio, split flow rate, inlet temperature, inlet pressure, MS/MS source temperature, GC/MS/MS interface temperature, MS/MS quadrupole temperature, MS1 quadrupole voltage, MS2 quadrupole voltage, repeller voltage, extractor voltage, electron energy voltage and MS/MS run time. The relevant MRM transitions are: $m / z, 369 \rightarrow m / z, 368,369 \rightarrow m / z, 354,369 \rightarrow m / z, 280$ and $m / z, 372$ $\rightarrow m / z$ 371, $m / z 372 \rightarrow m / z$ 357, $m / z, 372 \rightarrow m / z 283$ for FapyAde and FapyAde- ${ }^{13} \mathrm{C},{ }^{15} \mathrm{~N}_{2}$, respectively; $m / z, 457 \rightarrow m / z$ 442, $m / z 457 \rightarrow m / z, 368$ and $m / z$ 460 $\rightarrow m / z$ 445, $m / z, 460 \rightarrow$ $m / z, 371$ for FapyGua and FapyGua- ${ }^{13} \mathrm{C},{ }^{15} \mathrm{~N}_{2}$, respectively; $m / z, 455 \rightarrow m / z, 440$ and $\mathrm{m} / \mathrm{z}$ $460 \rightarrow m / z 445$ for 8-OH-Gua and 8-OH-Gua- ${ }^{15} \mathrm{~N}_{5}$, respectively; $m / z \quad 367 \rightarrow m / z \quad 352$ and $m / z 370 \rightarrow m / z 355$ for $8-\mathrm{OH}$-Ade and 8-OH-Ade- ${ }^{13} \mathrm{C},{ }^{15} \mathrm{~N}_{2}$, respectively; $m / z \quad 343 \rightarrow m / z$ $342, m / z 343 \rightarrow m / z 328$ and $m / z \quad 346 \rightarrow m / z$ 345, $m / z \quad 346 \rightarrow m / z 331$ for 5-OH-Cyt and 5-OH-Cyt- ${ }^{13} \mathrm{C},{ }^{15} \mathrm{~N}_{2}$, respectively; $\mathrm{m} / \mathrm{z} 344 \rightarrow \mathrm{m} / \mathrm{z} 343, \mathrm{~m} / \mathrm{z} 344 \rightarrow \mathrm{m} / \mathrm{z} 329$ and $\mathrm{m} / \mathrm{z} 350 \rightarrow$ $m / z$ 349, $m / z, 350 \rightarrow m / z, 335$ for 5-OH-Ura and 5-OH-Ura- ${ }^{13} \mathrm{C}_{4},{ }^{15} \mathrm{~N}_{2}$, respectively; $\mathrm{m} / z$ $358 \rightarrow m / z 343$ and $m / z \quad 362 \rightarrow m / z 347$ for 5-OH-MeUra and 5-OH-MeUra- ${ }^{13} \mathrm{C}_{2}, \mathrm{~d}_{2}$, respectively; $m / z, 448 \rightarrow m / z$ 433, $m / z, 448 \rightarrow m / z, 259$ and $m / z$ 452 $\rightarrow m / z$ 437, $m / z, 452 \rightarrow$ $m / z 262$ for ThyGly and ThyGly-d ${ }_{2}$, respectively and $m / z, 331 \rightarrow m / z, 331$ and $m / z, 334 \rightarrow$ $m / z 334$ for 5-OH-5MeHyd and 5-OH-5MeHyd- ${ }^{13} \mathrm{C},{ }^{15} \mathrm{~N}_{2}$, respectively [24].

6.2.5 The MRM current profiles are integrated using appropriate peak integration software and the measured lesion levels are determined using the MRM area ratios from the DNA lesion of interest and its labeled analogue in conjunction with the known amount of the labeled analogue initially spiked into each sample.

\section{Abbreviations}

5-OH-Cyt
5-OH-Ura
5-(OHMe)Ura
5-OH-5-MeHyd
8-OH-Ade
8-OH-Gua
FapyAde
FapyGua
BSTFA
DTT
EDTA
ENM
NP
MRM
SRM
ThyGly
UV/Vis

5-hydroxycytosine
5-hydroxyuracil
5-(hydroxymethyl)uracil
5-hydroxy-5-methylhydantoin
8-hydroxyadenine
8-hydroxyguanine
4,6-diamino-5-formamidopyrimidine
2,6-diamino-4-hydroxy-5-formamidopyrimidine
bis(trimethylsilyl)trifluoroacetamide
dithiothreitol
ethylenediaminetetraacetic acid
engineered nanomaterial
nanoparticle
multiple-reaction-monitoring
standard reference material
thymine glycol
ultraviolet-visible




\section{Acknowledgements}

We thank Julian Taurozzi and Vince Hackley of NIST for their helpful advice and discussions regarding the dispersion and characterization of the $\mathrm{P} 25 \mathrm{TiO}_{2}$ NPs (NIST SRM 1898) utilized in this study and other studies and for the use of their LDS system.

\section{$9 \quad$ References}

1. Petersen, E.J., et al., Identification and avoidance of potential artifacts and misinterpretations in nanomaterial ecotoxicity measurements. Environmental Science \& Technology, 2014. 48(8): p. 4226-4246.

2. Petersen, E.J. and B.C. Nelson, Mechanisms and measurements of nanomaterial-induced oxidative damage to DNA. Analytical and Bioanalytical Chemistry, 2010. 398: p. 613-650.

3. Gerloff, K., et al., Cytotoxicity and oxidative DNA damage by nanoparticles in human intestinal caco-2 cells. Nanotoxicology, 2009. 3(4): p. 355-364.

4. Lin, M.H., et al., Comparison of organic and inorganic germanium compounds in cellular radiosensitivity and preparation of germanium nanoparticles as a radiosensitizer. International Journal of Radiation Biology, 2009. 85(3): p. 214-226.

5. Rajapakse, K., et al., Experimental evidence of false-positive comet test results due to $\mathrm{TiO}_{2}$ particle - assay interactions. Nanotoxicology, 2013. 7(5): p. 1043-1051.

6. Karlsson, H.L., The comet assay in nanotoxicology research. Analytical and Bioanalytical Chemistry, 2010. 398(2): p. 651-666.

7. Nelson, B.C., et al., NIST gold nanoparticle reference materials do not induce oxidative DNA damage. Nanotoxicology, 2013. 7(1): p. 21-29.

8. Atha, D.H., et al., Copper oxide nanoparticle mediated DNA damage in terrestrial plant models. Environmental Science \& Technology, 2012. 46(3): p. 1819-1827.

9. Petersen, E.J., et al., Protective roles of single-wall carbon nanotubes in ultrasonication-induced DNA base damage. Small, 2013. 9(2): p. 205-208.

10. Singh, N., et al., The role of iron redox state in the genotoxicity of ultrafine superparamagnetic iron oxide nanoparticles. Biomaterials, 2012. 33(1): p. 163-170.

11. Petersen, E.J., et al., DNA damaging potential of photoactivated P25 titanium dioxide nanoparticles. Chemical Research in Toxicology, 2014. 27(10): p. 1877-1884.

12. Hunt, P.R., et al., Nanosilver suppresses growth and induces oxidative damage to DNA in Caenorhabditis elegans. Journal of Applied Toxicology, 2013. 33(10): p. 1131-42.

13. Evans, M.D., M. Dizdaroglu, and M.S. Cooke, Oxidative DNA damage and disease: Induction, repair and significance. Mutation Research-Reviews In Mutation Research, 2004. 567(1): p. 1-61.

14. Nelson, V.C., Synthesis of isotopically labelled DNA degradation products for use in mass spectrometric studies of cellular DNA damage. Journal of Labelled Compounds and Radiopharmaceuticals, 1996. 38(8): p. 713-723.

15. ASTM (American Society for Testing Materials) International, E2456-06: Standard terminology relating to nanotechnology, 2006: West Conshohocken, PA.

16. ISO (International Organization for Standardization), Ts 80004-1: Nanotechnologies Vocabulary - part 1: Core terms, 2010: Geneva, Switzerland.

17. Singer, V.L., et al., Characterization of picogreen reagent and development of a fluorescencebased solution assay for double-stranded DNA quantitation. Analytical Biochemistry, 1997. 249(2): p. 228-38.

18. Lowry, O.H., et al., Protein measurement with the folin phenol reagent. Journal of Biological Chemistry, 1951. 193: p. 265-275. 
19. Bradford, M.M., Rapid and sensitive method for quantitation of microgram quantities of protein utilizing principle of protein-dye binding. Analytical Biochemistry, 1976. 72(1-2): p. 248-254.

20. Reddy, P.T., et al., Stable isotope-labeling of DNA repair proteins, and their purification and characterization. Protein Expression and Purification, 2011. 78(1): p. 94-101.

21. Dizdaroglu, M., The use of capillary gas-chromatography mass-spectrometry for identification of radiation-induced DNA base damage and DNA base amino acid cross links. Journal of Chromatography A, 1984. 295(1): p. 103-121.

22. Dizdaroglu, M., Application of capillary gas-chromatography mass-spectrometry to chemical characterization of radiation-induced base damage of DNA : Implications for assessing DNArepair processes. Analytical Biochemistry, 1985. 144(2): p. 593-603.

23. Dizdaroglu, M., Quantitative determination of oxidative base damage in DNA by stable isotopedilution mass spectrometry. FEBS Letters, 1993. 315(1): p. 1-6.

24. Reddy, P.T., et al., Identification and quantification of human DNA repair protein NEIL1 by liquid chromatography/isotope dilution tandem mass spectrometry. Journal of Proteome Research, 2013. 12: p. 1049-1061.

25. Akbulut, O., et al., Separation of nanoparticles in aqueous multiphase systems through centrifugation. Nano Letters, 2012. 12(8): p. 4060-4064.

26. Arrighi, F.E., et al., Buoyant densities of DNA of mammals. Biochemical Genetics, 1970. 4(3): $p$. 367-376.

27. Panijpan, B., Buoyant density of DNA and $G+C$ content. Journal of Chemical Education, 1977. 54(3): p. 172-173.

28. Shi, H.B., et al., Titanium dioxide nanoparticles: A review of current toxicological data. Particle and Fibre Toxicology, 2013. 10: online access.

29. Zhang, F., Q. Jin, and S.W. Chan, Ceria nanoparticles: Size, size distribution, and shape. Journal of Applied Physics, 2004. 95(8): p. 4319-4326. 


\section{Appendix}

1. Removal of Engineered Nanomaterials from DNA Solutions Using Centrifugation Techniques

In the present study, we are strictly concerned with the separation of one discrete size and shape of ENM from a solution matrix of completely solubilized ct-DNA in aqueous buffer. Based on the constant buoyancy and density of the solution matrix, we can utilize the centrifugal force from a fixed-angle rotor centrifuge to separate the ENMs from the DNA solution. We are able to effect an almost $100 \%$ separation of ENMs from the DNA solution due to the fact that the DNA solution has a lower density $(\rho)$ than the density of the relevant ENMs $\left(\rho_{\mathrm{DNA}}=1.7 \mathrm{~g} / \mathrm{cm}^{3}\right.$ and $\rho_{\text {AuNPs }}=19.3 \mathrm{~g} / \mathrm{cm}^{3}, \rho_{\mathrm{TiO} 2 \mathrm{NPs}}=4.3 \mathrm{~g} / \mathrm{cm}^{3}$ ) [25-28]. Therefore, the ENMs can be forced to sediment at the bottom of the DNA solution using appropriate centrifugation speeds and times. When the centrifugation speed is held constant, and assuming spherical particles for simplicity, the appropriate centrifugation time for separating the ENM from the DNA solution can be determined empirically or it can be estimated theoretically using the following equations [29]:

$$
\begin{aligned}
& \text { (1) } v_{t}=\frac{\omega^{2} r\left(\rho_{\rho}-\rho_{i}\right) d_{\rho}^{2}}{18 \eta} \\
& \text { (2) } v_{t}=\frac{d_{r}}{d_{t}}
\end{aligned}
$$$$
\text { (3) } t_{t}=\frac{\left[\ln \frac{r_{\max }}{r_{\min }}\right]}{v_{t}} \text {, }
$$

where $v_{t}$ is the terminal velocity, $\omega^{2}$ is the angular velocity of the rotor, $\rho_{\rho}$ and $\rho_{i}$ are the density of the ENM and solution matrix (solubilized ct-DNA), respectively, $d_{\rho}$ is the diameter of the ENM, $\eta$ is the viscosity of the solution matrix, $r_{\max }$ and $r_{\min }$ are the maximum and minimum rotor radii, respectively, and $t_{t}$ is the total time for complete separation of the ENM from the solution matrix. 


\section{Figure 1}

Results from the removal of $10 \mathrm{~nm}, 30 \mathrm{~nm}$ and $60 \mathrm{~nm}$ NIST SRM AuNPs from aqueous buffered solutions containing $500 \mu \mathrm{g} / \mathrm{mL}$ ctDNA using centrifugation.

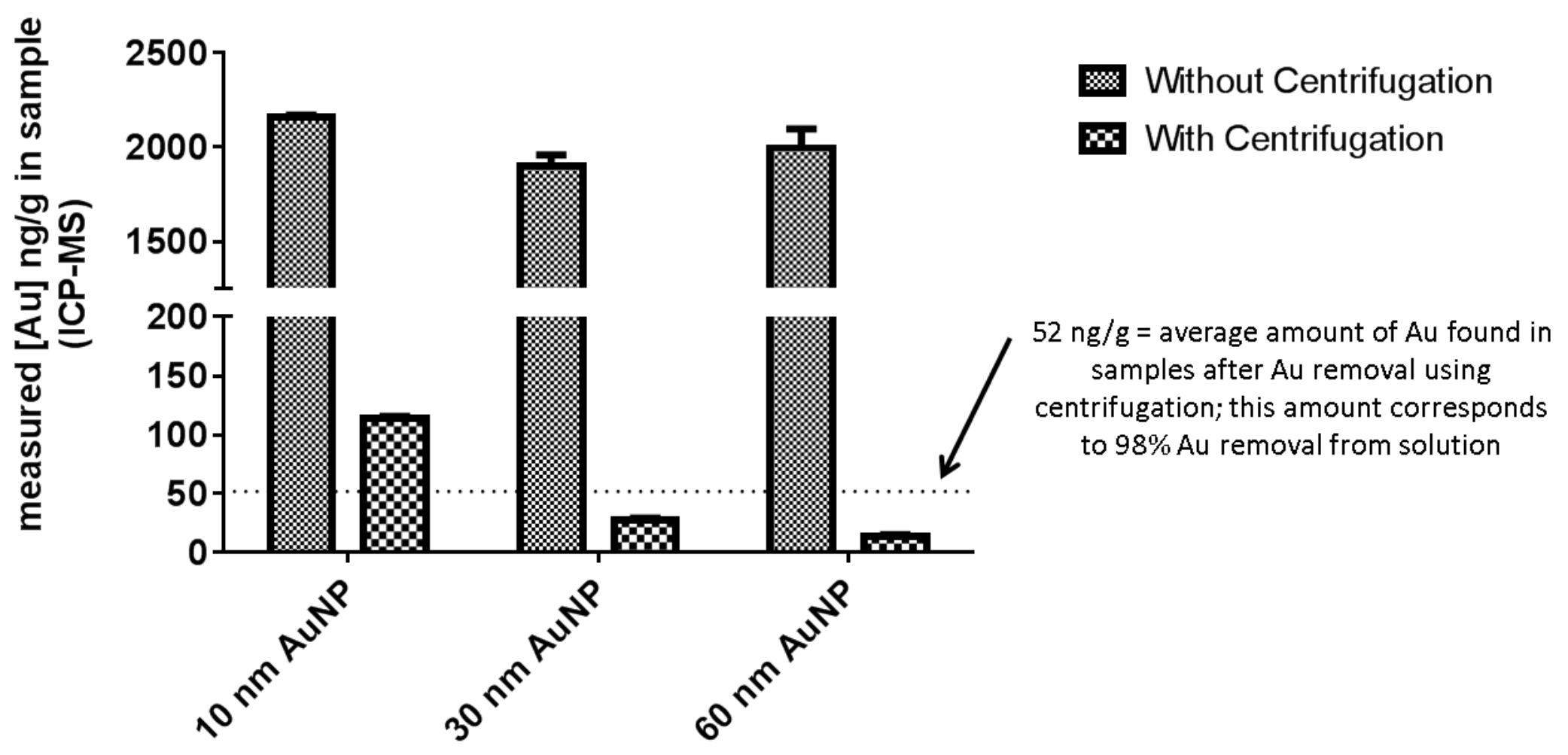


3. Table 1

Removal of NIST P25 $\mathrm{TiO}_{2}$ NPs from $500 \mu \mathrm{g} / \mathrm{mL}$ ct-DNA aqueous buffer solutions using centrifugation.

\begin{tabular}{|c|c|c|c|c|}
\hline Sample \# & $\begin{array}{c}\text { Detected Level of TiO } \\
(\mu \mathrm{g}) \text { after centrifugation }\end{array}$ & Standard Deviation $(\mu \mathrm{g})$ & $\begin{array}{c}\text { Expected Level of TiO } \mathbf{T}_{2} \\
(\boldsymbol{\mu g}) \text { before } \\
\text { centrifugation }\end{array}$ & \% TiO $_{2}$ Removed \\
\hline 1 & 7.516 & 0.019 & 198 & 96.2 \\
\hline 2 & 3.165 & 0.028 & 198 & 98.4 \\
\hline 3 & 2.109 & 0.010 & & \\
\hline
\end{tabular}

Ti was detected in the aqueous ct-DNA samples using ICP-OES and converted to TiO2 levels in the samples. The data shown are for three independently prepared samples that were analyzed 5 times each. The mean percentage of $\mathrm{TiO}_{2}$ removed was $97.8 \% \pm 1.4 \%$. 